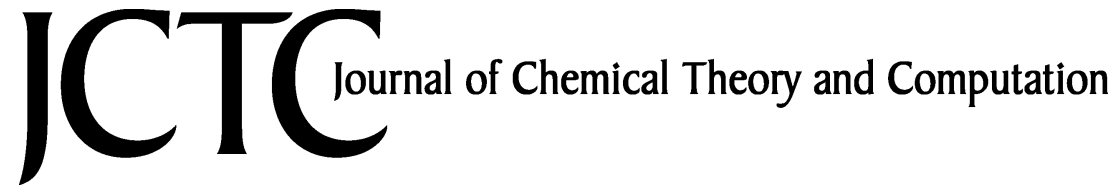

\section{Application of the Correlation Consistent Composite Approach (ccCA) to Third-Row (Ga-Kr) Molecules}

\author{
Nathan J. DeYonker,* Benjamin Mintz, Thomas R. Cundari, and Angela K. Wilson* \\ Center for Advanced Scientific Computing and Modeling (CASCaM), Department of \\ Chemistry, University of North Texas, Denton, Texas 76203-5070
}

Received September 24, 2007

\begin{abstract}
The correlation consistent composite approach (ccCA) has been applied to the G3/05 training set of 51 energetic properties for the atoms and molecules that contain the $4 p$ elements, $\mathrm{Ga}-\mathrm{Kr}$. When atomic and molecular first-order spin orbit coupling corrections are added to open shell atoms and molecules, the ccCA has a mean absolute deviation from experiment (MAD) of $0.95 \mathrm{kcal} \mathrm{mol}^{-1}$, an improvement of $0.10 \mathrm{kcal} \mathrm{mol}^{-1}$ over G3 and G3X model chemistries. The performance of the ccCA on third-row-containing atoms and molecules is, therefore, commensurate in accuracy with previous studies on lighter main group elements $\mathrm{H}-$ Ar. While the typical methods used to compute theoretical molecular spin orbit corrections may go against the spirit of "black box" model chemistries, such corrections may be necessary for molecules containing heavy elements such as $\mathrm{Ga}-\mathrm{Kr}$. For example, when second-order spin orbit corrections are added to the atomic and molecular energies, the ccCA MAD is reduced to $0.88 \mathrm{kcal} \mathrm{mol}^{-1}$.
\end{abstract}

\section{Introduction}

Sophisticated ab initio techniques that include electron correlation generally scale as $N^{5}$ or higher, where $N$ is the number of basis functions included in the basis set. Due to this high scaling, correlated methods, such as coupled cluster including single, double, and quasiperturbative triple excitations $[\operatorname{CCSD}(\mathrm{T})]$, are not computationally tractable for large molecules when combined with large basis sets. Model chemistries, also called composite methods, attempt to effectively reproduce a more sophisticated level of ab initio theory by using combinations of more efficient levels of theory and basis sets in an additive manner. These additive corrections form the foundation of composite model chemistries and have repeatedly been shown to be a valid and cost-effective approximation to the electronic Schrödinger equation. Model chemistries allow for quantitative computational studies on significantly larger chemical systems that would normally be inaccessible.

The correlation consistent Composite Approach (ccCA) has been recently developed in our laboratories and is a

* Corresponding author e-mail: ndeyonk@unt.edu (N.J.D.), akwilson@unt.edu (A.K.W.). model chemistry based on second-order Møller-Plesset perturbation theory computations extrapolated to the complete basis set (CBS) limit. ${ }^{1,2}$ The ccCA utilizes the family of correlation consistent basis sets pioneered by Dunning and co-workers. ${ }^{3-10}$ The initial purpose for creating the ccCA was to provide an efficient MP2-based model chemistry that did not require parametrization. Benchmark studies utilizing the ccCA have shown that it reliably achieves "chemical accuracy", defined as obtaining energetic properties within $1 \mathrm{kcal} \mathrm{mol}^{-1}$ of well-established experimental values for main group species, without relying on optimized or semiempirical parameters.

Since its initial implementation, the ccCA generally has been shown to provide results that are comparable to $\mathrm{G} 3^{11-14}$ and $\mathrm{G} 3 \mathrm{X}^{15}$ for organic species ${ }^{1,2,16}$ and more reliable than these widely used model chemistries for inorganic s-block species. ${ }^{17}$ Since the suite of correlation consistent basis sets also exists for transition metals $\mathrm{Sc}-\mathrm{Zn},{ }^{5}$ the ccCA has also been applied to a test set of transition metal-containing species, and an accuracy of $\pm 3 \mathrm{kcal} \mathrm{mol}^{-1}$ has been achieved for enthalpies of formation. ${ }^{18}$ The ccCA can also be utilized for high-accuracy studies on larger molecular species such as magnesocene $\left[\mathrm{Mg}\left(\mathrm{C}_{5} \mathrm{H}_{5}\right)_{2}\right]$ and beryllium bis(acetyl- 
acetonate) $\left[\mathrm{Be}\left(\mathrm{C}_{5} \mathrm{H}_{7} \mathrm{O}_{2}\right)_{2}\right]^{19}$ that are currently computationally intractable for studies employing large basis set coupled cluster computations, such as those within the $\mathrm{W} n,{ }^{20,21}$ HEAT, ${ }^{22}$ and Dixon/Feller/Peterson ${ }^{23-30}$ model chemistries.

Thus far, the ccCA method has been benchmarked using the $\mathrm{G} n$ training sets. ${ }^{1,2}$ The most current iteration of the $\mathrm{G} n$ training sets, G3/05, contains 464 first-, second- ${ }^{11}$ and thirdrow ${ }^{14,31-34}$ atomic and molecular species and includes experimental enthalpies of formation, ionization potentials, electron affinities, and proton affinities. However, because of a lack of core-valence correlation consistent basis sets, atomic and molecular properties of species that contain thirdrow $(\mathrm{K}-\mathrm{Kr})$ atoms have not yet been examined with the ccCA model chemistry. Recently, we have developed the necessary cc-pCVnZ basis sets for $\mathrm{Ga}-\mathrm{Kr} .{ }^{35}$ Thus, with the addition of these basis sets to the suite of correlation consistent basis sets, ccCA calculations are now possible for all elements up to krypton $(Z=36)$ with the exception of potassium and calcium. We now extend the investigation of the ccCA model chemistry to the properties of G3/05 molecules that contain the elements $\mathrm{Ga}$ through $\mathrm{Kr}$.

\section{Theoretical Methods}

$\mathrm{Ab}$ initio and DFT computations were carried out with the Gaussian03 software package. ${ }^{36}$ Structures were optimized at the B3LYP level of theory with the cc-pVTZ basis sets. Harmonic vibrational frequencies were then computed using the B3LYP/cc-pVTZ level of theory at the geometric stationary points. To obtain the required zero-point vibrational energies (ZPE) and temperature-dependent enthalpy corrections, the harmonic frequencies were scaled by a factor of 0.9854 to account for known deficiencies in the harmonic approximation. The use of B3LYP/cc-pVTZ for optimizing geometries and obtaining harmonic frequencies provides results that are quite similar to those obtained via $6-31 \mathrm{G}(2 d f, p)$ optimizations that are computed with the G3X and G4 model chemistries. The current formulation of the ccCA employs MP2 extrapolations to the complete basis set limit (CBS) and the previous ccCA benchmark study found that two types of CBS extrapolations provided the most reliable results for the main group G3/99 training set. ${ }^{2}$ The first is the Peterson mixed exponential/Gaussian function extrapolation scheme ${ }^{37}$ defined by the formula

$$
E(x)=E_{\mathrm{CBS}}+B \exp [-(x-1)]+C \exp \left[-(x-1)^{2}\right]
$$

where $x=2,3$, and 4 come from aug-cc-pVDZ, aug-ccpVTZ, and aug-cc-pVQZ MP2 energies, respectively. The other CBS extrapolation is the two-point Schwartz $1 /\left(l_{\max }{ }^{4}\right)$ scheme $^{38-40}$ using aug-cc-pVTZ and aug-cc-pVQZ MP2 energies and is determined using the formula

$$
E\left(l_{\max }\right)=E_{\mathrm{CBS}}+\frac{B}{\left(l_{\max }+\frac{1}{2}\right)^{4}}
$$

where $l_{\max }$ is the maximum angular momentum value within the basis set. In this study, $l_{\max }=3$ for aug-cc-pVTZ and $l_{\max }=4$ for aug-cc-pVQZ energies. We refer to the ccCA which utilizes the extrapolation function in eq 1.1 as ccCA-
$\mathrm{P}$, and the ccCA which utilizes the extrapolation function in eq 1.2 as ccCA-S4.

After the MP2 CBS energy is determined, a series of additive corrections is computed. In order to properly account for high-order electron correlation effects, a single point energy is computed at the triple- $\zeta$ level with the $\operatorname{CCSD}(\mathrm{T})$ wave function. The $\triangle E(C C)$ correction for the ccCA methods can be expressed as

$$
\Delta E(\mathrm{CC})=E[\mathrm{CCSD}(\mathrm{T}) / \mathrm{cc}-\mathrm{pVTZ}]-E[\mathrm{MP} 2 / \mathrm{cc}-\mathrm{pVTZ}]
$$

Next, scalar relativistic corrections are obtained from frozencore MP2 wave functions using the cc-pVTZ-DK ${ }^{41}$ basis sets and the spin-free, one-electron Douglas-Kroll-Hess (DKH) Hamiltonian. ${ }^{42-44}$ The MP2 relativistic correction to the ccCA energy, $\Delta E(\mathrm{DK}),{ }^{45}$ is formulated as

$$
\Delta E(\mathrm{DK})=E[\mathrm{MP} 2 / \mathrm{cc}-\mathrm{pVTZ}-\mathrm{DK}]-E[\mathrm{MP} 2 / \mathrm{cc}-\mathrm{pVTZ}]
$$

The final computation is a correction for core-valence correlation effects. This energy, $\Delta E(\mathrm{CV})$, is computed as

$$
\begin{array}{r}
\Delta E(\mathrm{CV})=E[\mathrm{MP} 2(\text { full)/aug-cc-pCVTZ }]- \\
E[\mathrm{MP} 2 / \text { aug-cc-pVTZ }]
\end{array}
$$

Including the zero-point energy $[\triangle \mathrm{E}(\mathrm{ZPE})]$ determined by the scaled B3LYP/cc-pVTZ harmonic vibrational frequencies, the ccCA-CBS energy is defined as

$$
\begin{array}{r}
E_{0}(\mathrm{ccCA}-\mathrm{CBS})=E[\mathrm{MP} 2 / \text { aug-cc-pV } \infty \mathrm{Z}]+\Delta E(\mathrm{CC})+ \\
\Delta E(\mathrm{DK})+\Delta E(\mathrm{CV})+\Delta E(\mathrm{ZPE})
\end{array}
$$

For atomic species, ${ }^{46}$ and some linear molecules (discussed below), a spin orbit correction, taken from previous theoretical studies, $\Delta(\mathrm{SO}),{ }^{14,31}$ is also added to the ccCA energy.

\section{Evaluation of ccCA Methods for Species with Elements $\mathrm{Ga}-\mathrm{Kr}$}

A. Application of ccCA to G3/05 Set of Atoms and Molecules with Elements $\mathbf{G a}-\mathbf{K r}$. Tabulated experimental uncertainties of $\pm 1.0 \mathrm{kcal} \mathrm{mol}^{-1}$ or less is a main criterion for inclusion within the $\mathrm{G} n$ test sets. Therefore, the G3/05 training set is a very stringent test of any new ab initio methodology. ${ }^{11}$ The third-row molecules investigated are obtained from the G3/05 set but do not include the K- and Ca-containing molecules (and their respective ions) as full sets of core-valence correlation consistent basis sets currently do not exist for those elements. However, development of the complete set of correlation consistent basis sets necessary for ccCA computations of molecules containing potassium and calcium is currently in progress in our laboratory, and the ccCA model chemistry will soon be available and benchmarked for the entire periodic table through krypton.

In all, the $\mathrm{G} 3 / 05$ test set for elements $\mathrm{Ga}-\mathrm{Kr}$ contains 51 systems: 19 atomization energies $\left(D_{0}\right), 11$ enthalpies of formation $\left(\Delta H_{\mathrm{f}}\right), 15$ ionization potentials (IP), 4 electron affinities (EA), and 2 proton affinities (PA). Table 1 shows ccCA energies for the atoms $\mathrm{Ga}-\mathrm{Kr}$ as well as the spinorbit correction energies. Geometric parameters for the 51 
Table 1. Atomic ccCA Energies for the Elements $\mathrm{Ga}-\mathrm{Kr}$

\begin{tabular}{lcccc}
\hline & ccCA-P & ccCA-S4 & $\Delta E(\mathrm{SO})^{a}$ & $\Delta E^{(2)}(\mathrm{SO})^{b}$ \\
\hline $\mathrm{Ga}^{2} \mathrm{P}_{1 / 2}$ & -1943.067544 & -1943.069629 & -0.00251 & -0.00002 \\
$\mathrm{Ge}^{3} \mathrm{P}_{0}$ & -2097.939639 & -2097.941788 & -0.00441 & -0.00020 \\
$\mathrm{As}^{4} \mathrm{~S}_{3 / 2}$ & -2259.905472 & -2259.907698 & 0.0 & -0.00047 \\
$\mathrm{Se}^{3} \mathrm{P}_{2}$ & -2428.979165 & -2428.981410 & -0.00430 & -0.00081 \\
$\mathrm{Br}^{2} \mathrm{P}_{3 / 2}$ & -2605.350744 & -2605.352995 & -0.00560 & -0.00049 \\
$\mathrm{Kr}^{1} \mathrm{~S}_{0}$ & -2789.137674 & -2789.139744 & 0.0 & -0.00076 \\
\hline
\end{tabular}

a Experimental first-order atomic SO corrections are obtained from ref 46. ${ }^{b}$ Theoretical second-order atomic SO corrections are obtained from ref 31.

systems in the third-row set are given in Table S1 (Supporting Information).

When applying the ccCA model chemistry to atoms and molecules with third-row elements, a caveat of the frozen core approximation must be discussed. The valence correlation consistent basis sets for elements $\mathrm{Ga}-\mathrm{Kr}$ were developed with frozen $1 s, 2 s, 2 p, 3 s, 3 p$, and $3 d$ molecular orbitals (MOs); therefore, "valence" correlated MOs of the atoms and molecules in this training set include only $4 s$ and $4 p$ MOs. The recently created core-valence basis sets have active $3 s, 3 p, 4 s, 3 d$, and $4 p$ MOs, which will be necessarily correlated in order to compute the $\Delta E(\mathrm{CV})$ additive correction, shown in eq 1.5.

For the third-row G3/05 training set (with third-row elements $\mathrm{Ga}-\mathrm{Kr}$ only), deviations from experimental values are given in Table 2 for ccCA-P, ccCA-S4, G3, G3X, and $\mathrm{G} 4$ theories. For the $\mathrm{Ga}-\mathrm{Kr}$ containing species in the $\mathrm{G} 3 /$ 05 training set, the ccCA can reliably predict energetic properties to within chemical accuracy. The mean signed deviation (MSD) is $-0.02 \mathrm{kcal} \mathrm{mol}^{-1}$ for ccCA-P and 0.07 $\mathrm{kcal} \mathrm{mol}^{-1}$ for ccCA-S4, indicating almost no overall bias in the reliability of the ccCA. The mean absolute deviation (MAD) for ccCA-P is $0.95 \mathrm{kcal} \mathrm{mol}^{-1}$, and slightly larger for ccCA-S4, $1.00 \mathrm{kcal} \mathrm{mol}^{-1}$. The maximum absolute deviations for the ccCA model chemistries are for the $\Delta H_{\mathrm{f}}$ of $\mathrm{C}_{5} \mathrm{H}_{8} \mathrm{Br}_{2}$ (2.9 and $3.4 \mathrm{kcal} \mathrm{mol}^{-1}$ for ccCA-P and ccCA$\mathrm{S} 4$, respectively) and the IP of $\mathrm{NaBr}\left(5.2\right.$ and $5.0 \mathrm{kcal} \mathrm{mol}^{-1}$ for ccCA-P and ccCA-S4, respectively). Absolute deviation from experiment for the properties of these two molecules is quite large for G3 methods as well ( 3.2 and $4.9 \mathrm{kcal} \mathrm{mol}^{-1}$, respectively), but the G4 $\Delta H_{\mathrm{f}}$ value of $\mathrm{C}_{5} \mathrm{H}_{8} \mathrm{Br}_{2}$ is only 1.9 kcal mol ${ }^{-1}$ away from experiment. ${ }^{47}$

For the 51 quantities computed in the training set, the ccCA-P is an improvement of $0.10 \mathrm{kcal} \mathrm{mol}^{-1}$ over the G3X model chemistry, which has a MAD of $1.07 \mathrm{kcal} \mathrm{mol}^{-1}$. The ccCA methods also outperform all of the CBS- $n$ methods ${ }^{48-50}$ that have been benchmarked for the 40 third-row-containing atoms and molecules in the older G3/99 set. ${ }^{51}$ For these same 40 energetic properties ( $19 D_{0}, 15$ IPs, 4 EAs, and 2 PAs), the ccCA-P and ccCA-S4 MADs are 0.79 and $0.78 \mathrm{kcal}$ mol $^{-1}$, respectively, while the best CBS- $n$ method, CBSQB3, has a MAD of $1.12 \mathrm{kcal} \mathrm{mol}^{-1}$. Previous CBS CCSD(T) studies in our laboratory have been carried out on the $\mathrm{G} 3$ test set of molecules containing $\mathrm{Ga}-\mathrm{Kr}^{5}{ }^{52,53}$ Interestingly, the ccCA model chemistry has a lower MAD with the third-row test set than most CBS CCSD(T) methods using valence aug-cc-pVnZ and relativistic pseudopotential augcc-pVnZ basis sets. Depending on the CBS extrapolation
Table 2. Deviations of ccCA and $\mathrm{G} n$ Methods from Experiment (Expt-Theory) in $\mathrm{kcal} \mathrm{mol}^{-1}$ for the Third-Row G3/05 Training Set

\begin{tabular}{|c|c|c|c|c|c|c|c|}
\hline property & species & $\operatorname{expt}^{a}$ & ccCA-P & ccCA-S4 & $\mathrm{G}^{b}$ & $\mathrm{G} 3 \mathrm{X}^{b}$ & $\mathrm{G} 4^{c}$ \\
\hline \multirow[t]{19}{*}{$D_{0}$} & $\mathrm{GeH}_{4}$ & 270.5 & -2.7 & -2.8 & -2.5 & -2.8 & -2.5 \\
\hline & $\mathrm{AsH}$ & 64.6 & 1.6 & 1.6 & -0.1 & -0.4 & 0.7 \\
\hline & $\mathrm{AsH}_{2}$ & 131.1 & -0.7 & -0.7 & -0.8 & -1.2 & -0.7 \\
\hline & $\mathrm{AsH}_{3}$ & 206.0 & 0.3 & 0.3 & 1.4 & 0.8 & 1.3 \\
\hline & $\mathrm{SeH}$ & 74.3 & -0.7 & -0.7 & -1.1 & -1.1 & -0.7 \\
\hline & $\mathrm{SeH}_{2}$ & 153.2 & -0.4 & -0.4 & 0.9 & 0.6 & 1.1 \\
\hline & $\mathrm{HBr}$ & 86.5 & -0.8 & -0.8 & -0.2 & 0.0 & 0.4 \\
\hline & $\mathrm{GaCl}$ & 109.9 & 0.4 & 0.4 & -1.5 & -1.3 & -0.6 \\
\hline & $\mathrm{GeO}$ & 155.2 & -2.1 & -2.1 & -1.6 & -3.0 & -1.0 \\
\hline & $\mathrm{As}_{2}$ & 91.3 & -1.1 & -1.0 & -0.4 & -1.6 & -0.4 \\
\hline & $\mathrm{BrCl}$ & 51.5 & -0.2 & -0.2 & 0.3 & 0.5 & 0.5 \\
\hline & $\mathrm{BrF}$ & 58.9 & -0.2 & -0.2 & 0.3 & -0.2 & -0.4 \\
\hline & $\mathrm{BrO}$ & 55.3 & 0.6 & 0.6 & 0.1 & -0.1 & 0.3 \\
\hline & $\mathrm{Br}_{2}$ & 45.4 & -0.5 & -0.6 & -0.1 & 0.1 & 0.9 \\
\hline & $\mathrm{BBr}$ & 103.5 & 1.2 & 1.2 & 0.7 & 1.1 & 1.5 \\
\hline & $\mathrm{NaBr}$ & 86.2 & -0.4 & -0.3 & -2.1 & -1.9 & -0.7 \\
\hline & $\mathrm{CH}_{3} \mathrm{Br}$ & 358.2 & -0.7 & -0.9 & -0.3 & -0.1 & 0.4 \\
\hline & $\mathrm{GeS}_{2}$ & 191.7 & 1.5 & 1.6 & -1.9 & -2.5 & -1.2 \\
\hline & $\mathrm{KrF}_{2}$ & 21.9 & -0.2 & -0.2 & -0.6 & -1.3 & -1.7 \\
\hline \multirow[t]{11}{*}{$\Delta H_{\mathrm{f}}(298.15 \mathrm{~K})$} & $\mathrm{CF}_{3} \mathrm{Br}$ & -155.0 & 0.8 & 1.1 & 2.3 & 1.3 & 0.4 \\
\hline & $\mathrm{CCl}_{3} \mathrm{Br}$ & -10.0 & 1.2 & 1.2 & 2.9 & 2.2 & 1.4 \\
\hline & $\mathrm{C}_{2} \mathrm{H}_{3} \mathrm{Br}$ & 18.9 & 1.8 & 2.0 & 2.0 & 1.9 & 1.4 \\
\hline & $\mathrm{C}_{2} \mathrm{H}_{5} \mathrm{Br}$ & -14.8 & 1.6 & 1.9 & 1.2 & 0.9 & 0.3 \\
\hline & $\mathrm{C}_{3} \mathrm{H}_{7} \mathrm{Br}$ & -23.8 & 0.9 & 1.3 & 0.6 & 0.1 & -0.5 \\
\hline & $\mathrm{C}_{6} \mathrm{H}_{5} \mathrm{Br}$ & 25.2 & 0.1 & 0.5 & 1.5 & 1.4 & 1.2 \\
\hline & $\mathrm{C}_{6} \mathrm{H}_{13} \mathrm{Br}$ & -35.4 & 1.9 & 2.6 & 1.2 & 0.7 & 0.3 \\
\hline & $\mathrm{C}_{3} \mathrm{H}_{6} \mathrm{Br}_{2}$ & -17.1 & 2.8 & 3.1 & 2.7 & 2.2 & 1.0 \\
\hline & $\mathrm{CHF}_{2} \mathrm{Br}$ & -101.6 & 0.6 & 0.7 & 1.2 & 0.4 & -0.4 \\
\hline & $\mathrm{COBr}_{2}$ & -27.1 & 2.1 & 2.0 & 2.7 & 2.6 & 1.2 \\
\hline & $\mathrm{C}_{5} \mathrm{H}_{8} \mathrm{Br}_{2}$ & -13.1 & 2.9 & 3.4 & 3.2 & 3.1 & 1.9 \\
\hline \multirow[t]{15}{*}{ IP } & $\mathrm{Ga}$ & 138.3 & -0.2 & -0.1 & -0.2 & -0.2 & -0.6 \\
\hline & $\mathrm{Ge}$ & 182.2 & 0.0 & 0.0 & -0.1 & -0.1 & -0.2 \\
\hline & As & 225.7 & -0.4 & -0.4 & -0.4 & -0.3 & -0.3 \\
\hline & $\mathrm{Se}$ & 224.9 & 0.6 & 0.6 & 1.0 & 0.5 & 0.7 \\
\hline & $\mathrm{Br}$ & 272.4 & -0.4 & -0.2 & 0.5 & 0.9 & 0.4 \\
\hline & $\mathrm{Kr}$ & 322.8 & 0.3 & 0.5 & 1.3 & 0.9 & 1.2 \\
\hline & AsH & 222.3 & 0.1 & 0.0 & -1.0 & -1.0 & -0.5 \\
\hline & $\mathrm{AsH}_{2}$ & 217.8 & 0.3 & 0.3 & -0.8 & -0.8 & -0.6 \\
\hline & $\mathrm{SeH}$ & 227.0 & -1.3 & -1.2 & 0.1 & -0.1 & -0.6 \\
\hline & $\mathrm{SeH}_{2}$ & 228.0 & -1.2 & -1.1 & -0.3 & -0.4 & -0.4 \\
\hline & $\mathrm{HBr}$ & 268.9 & -0.3 & -0.2 & 0.8 & 0.8 & 1.0 \\
\hline & $\mathrm{Br}_{2}$ & 242.6 & -0.1 & 0.1 & -0.2 & -0.2 & 0.4 \\
\hline & $\mathrm{HOBr}$ & 245.3 & -1.6 & -1.4 & -0.4 & -0.6 & -0.2 \\
\hline & $\mathrm{BrF}$ & 271.7 & -0.1 & 0.1 & 0.7 & 0.8 & 1.4 \\
\hline & $\mathrm{NaBr}$ & 191.6 & -5.2 & -5.0 & -4.9 & -5.1 & -4.7 \\
\hline \multirow[t]{4}{*}{ EA } & $\mathrm{Ge}$ & 28.4 & 0.0 & 0.0 & -0.5 & -0.4 & -0.7 \\
\hline & $\mathrm{Br}$ & 77.6 & 0.1 & 0.3 & -0.5 & -0.9 & -0.7 \\
\hline & $\mathrm{BrO}$ & 54.5 & -1.6 & -1.5 & -1.3 & -1.2 & -1.5 \\
\hline & $\mathrm{SeH}$ & 51.0 & -0.5 & -0.5 & -0.4 & -0.5 & -0.5 \\
\hline \multirow[t]{2}{*}{ PA } & $\mathrm{Br}$ & 322.6 & -1.0 & -1.2 & -0.3 & 0.3 & 0.2 \\
\hline & $\mathrm{CH}_{3} \mathrm{Br}$ & 157.3 & 0.1 & 0.0 & 0.4 & 0.4 & 0.2 \\
\hline MSD & & & -0.02 & 0.07 & 0.11 & -0.09 & -0.01 \\
\hline MAD & & & 0.95 & 1.00 & 1.07 & 1.05 & 0.86 \\
\hline
\end{tabular}

${ }^{a}$ Experimental results are obtained from ref $14 .{ }^{b} \mathrm{G} 3$ and $\mathrm{G} 3 \mathrm{X}$ results are obtained from refs 14 and 11 , respectively. ${ }^{c} \mathrm{G} 4$ results are obtained from ref 47 .

scheme, the aug-cc-pVnZ MADs range from $0.89-1.21 \mathrm{kcal}$ $\mathrm{mol}^{-1}$ and the aug-cc-pVnZ-PP MADs range from $0.98-$ 
$1.42 \mathrm{kcal} \mathrm{mol}^{-1}$. While the MP2-based ccCA method might be expected to be inferior to $\operatorname{CCSD}(\mathrm{T})$-based CBS extrapolations, the treatment of core-valence effects in ccCA is likely the source of improved results over the previous large basis set coupled cluster data applied to the valence correlation space only. Last, a few popular density functional theories have MADs for the third-row set ranging from 2.50-5.41 $\mathrm{kcal} \mathrm{mol}^{-1}$ and are much less reliable than ccCA and currentgeneration $\mathrm{G} n$ model chemistries (cf. ref 11, Table 2).

Using first-order atomic and molecular spin orbit corrections, the ccCA MAD of $0.95-1.00 \mathrm{kcal} \mathrm{mol}^{-1}$ is worse than the new G4 method, which has a MAD of $0.86 \mathrm{kcal} \mathrm{mol}^{-1} .^{47}$ However, it is perhaps unsurprising that G4 is a significant improvement over ccCA as well as G3 and its variants. The G4 is parametrized with third-row species included in the HLC optimization, and the G4 HLC also contains six optimized parameters, rather than four as in the G3 generation. Unlike the study of s-block containing first- and secondrow molecules, where ccCA model chemistries obtain a greater number of energetic properties to within chemical accuracy than $\mathrm{G} n$ methods, ${ }^{17,19}$ the number of instances in $\mathrm{G} n$ and ccCA methods where the deviation has a magnitude less than $\pm 1.0 \mathrm{kcal} \mathrm{mol}^{-1}$ is similar, with a range of $31-36$ instances.

As shown in previous ccCA papers, $\mathrm{G} n$ theories rely on the HLC to provide a significant contribution to thermodynamic properties (such as atomization energies and enthalpies of formation).$^{1,47}$ It is known that the magnitude of this empirical contribution can be very large, especially with larger molecules, and that it is unable to fully account for basis set and electron correlation deficiencies. While the ccCA is an MP2-based model chemistry and lacks empirical parametrization, it is approximately an order of magnitude more computationally expensive for small- to medium-sized molecules than $\mathrm{G} n$ methods. For example, on eight SGI Origin MIPS R16000 processors, the ccCA energy of 1-bromohexane took $109 \mathrm{~h}$ to complete versus $9 \mathrm{~h}$ for the G3 energy on the same system. Again, it is pertinent to note that the most computationally expensive step of the ccCA method is usually the CCSD(T) cc-pVTZ computations. Thus ccCA is much less expensive than composite methods that are based on CBS limits of CCSD(T) energies.

B. Discussion of First- and Second-Order Spin Orbit Coupling. It was shown that first-order SOC corrections can alter molecular energies by up to $4.1 \mathrm{kcal} \mathrm{mol}^{-1}$ and that even second-order molecular SOC effects, computed in a study by Blaudeau and Curtiss, ${ }^{31}$ can affect atomization energies of molecules containing elements $\mathrm{Ga}-\mathrm{Kr}$ by up to $0.8 \mathrm{kcal} \mathrm{mol}^{-1}$. Inclusion of theoretical SOC corrections requires accurate computation of multireference wave functions, which in turn is troublesome for the development and benchmarking of single reference "black box" composite methods such as ccCA and $\mathrm{G} n$. Examples are detailed in Hess's comprehensive review of spin-orbit coupling computations ${ }^{54}$ as well as in work by Peterson which describes severe active space difficulties for ground and excited electronic states of a seemingly innocuous first-row diatomic $\left(\mathrm{BO}^{+}\right) .55$ The inclusion of SOC energies is, however, necessary for a proper ab initio treatment of open-shell heavy
Table 3. Deviations of ccCA Methods from Experiment (Expt-Theory) in kcal mol-1 for the Third-Row G3/05 Training Set When Atomic and Molecular Second-Order Spin Orbit Corrections Are Included in the Energies ${ }^{a}$

\begin{tabular}{|c|c|c|c|c|}
\hline property & species & $\operatorname{expt}^{b}$ & ccCA-P & ccCA-S4 \\
\hline \multirow[t]{19}{*}{$D_{0}$} & $\mathrm{GeH}_{4}$ & 270.5 & -2.7 & -2.7 \\
\hline & $\mathrm{AsH}$ & 64.6 & 1.5 & 1.5 \\
\hline & $\mathrm{AsH}_{2}$ & 131.1 & -0.5 & -0.6 \\
\hline & $\mathrm{AsH}_{3}$ & 206.0 & 0.6 & 0.6 \\
\hline & $\mathrm{SeH}$ & 74.3 & -0.2 & -0.2 \\
\hline & $\mathrm{SeH}_{2}$ & 153.2 & -0.2 & -0.2 \\
\hline & $\mathrm{HBr}$ & 86.5 & -0.9 & -0.9 \\
\hline & $\mathrm{GaCl}$ & 109.9 & 0.4 & 0.4 \\
\hline & $\mathrm{GeO}$ & 155.2 & -2.0 & -2.0 \\
\hline & $\mathrm{As}_{2}$ & 91.3 & -0.5 & -0.4 \\
\hline & $\mathrm{BrCl}$ & 51.5 & 0.1 & 0.1 \\
\hline & $\mathrm{BrF}$ & 58.9 & 0.1 & 0.1 \\
\hline & $\mathrm{BrO}$ & 55.3 & 0.9 & 0.9 \\
\hline & $\mathrm{Br}_{2}$ & 45.4 & -0.6 & -0.6 \\
\hline & $\mathrm{BBr}$ & 103.5 & 1.5 & 1.5 \\
\hline & $\mathrm{NaBr}$ & 86.2 & -0.1 & 0.0 \\
\hline & $\mathrm{CH}_{3} \mathrm{Br}$ & 358.2 & -0.4 & -0.6 \\
\hline & $\mathrm{GeS}_{2}$ & 191.7 & 1.6 & 1.7 \\
\hline & $\mathrm{KrF}_{2}$ & 21.9 & 0.3 & 0.2 \\
\hline \multirow[t]{11}{*}{$\Delta H_{\mathrm{f}}(298.15 \mathrm{~K})$} & $\mathrm{CF}_{3} \mathrm{Br}$ & -155.0 & 0.5 & 0.7 \\
\hline & $\mathrm{CCl}_{3} \mathrm{Br}$ & -10.0 & 0.9 & 0.9 \\
\hline & $\mathrm{C}_{2} \mathrm{H}_{3} \mathrm{Br}$ & 18.9 & 1.5 & 1.7 \\
\hline & $\mathrm{C}_{2} \mathrm{H}_{5} \mathrm{Br}$ & -14.8 & 1.3 & 1.6 \\
\hline & $\mathrm{C}_{3} \mathrm{H}_{7} \mathrm{Br}$ & -23.8 & 0.6 & 1.0 \\
\hline & $\mathrm{C}_{6} \mathrm{H}_{5} \mathrm{Br}$ & 25.2 & -0.2 & 0.2 \\
\hline & $\mathrm{C}_{6} \mathrm{H}_{13} \mathrm{Br}$ & -35.4 & 1.6 & 2.2 \\
\hline & $\mathrm{C}_{3} \mathrm{H}_{6} \mathrm{Br}_{2}$ & -17.1 & 2.2 & 2.5 \\
\hline & $\mathrm{CHF}_{2} \mathrm{Br}$ & -101.6 & 0.2 & 0.4 \\
\hline & $\mathrm{COBr}_{2}$ & -27.1 & 1.4 & 1.4 \\
\hline & $\mathrm{C}_{5} \mathrm{H}_{8} \mathrm{Br}_{2}$ & -13.1 & 2.3 & 2.8 \\
\hline \multirow[t]{15}{*}{ IP } & $\mathrm{Ga}$ & 138.3 & -0.2 & -0.2 \\
\hline & $\mathrm{Ge}$ & 182.2 & -0.1 & -0.1 \\
\hline & As & 225.7 & -0.7 & -0.7 \\
\hline & $\mathrm{Se}$ & 224.9 & 0.7 & 0.8 \\
\hline & $\mathrm{Br}$ & 272.4 & 0.2 & 0.3 \\
\hline & $\mathrm{Kr}$ & 322.8 & -0.2 & 0.1 \\
\hline & $\mathrm{AsH}$ & 222.3 & -0.3 & -0.3 \\
\hline & $\mathrm{AsH}_{2}$ & 217.8 & 0.4 & 0.4 \\
\hline & $\mathrm{SeH}$ & 227.0 & -0.4 & -0.4 \\
\hline & $\mathrm{SeH}_{2}$ & 228.0 & -1.1 & -1.1 \\
\hline & $\mathrm{HBr}$ & 268.9 & -0.7 & -0.6 \\
\hline & $\mathrm{Br}_{2}$ & 242.6 & -0.8 & -0.6 \\
\hline & $\mathrm{HOBr}$ & 245.3 & -1.6 & -1.4 \\
\hline & $\mathrm{BrF}$ & 271.7 & -0.1 & 0.1 \\
\hline & $\mathrm{NaBr}$ & 191.6 & -5.1 & -5.0 \\
\hline \multirow[t]{4}{*}{ EA } & $\mathrm{Ge}$ & 28.4 & 0.1 & 0.1 \\
\hline & $\mathrm{Br}$ & 77.6 & 0.4 & 0.6 \\
\hline & $\mathrm{BrO}$ & 54.5 & 0.9 & 0.9 \\
\hline & $\mathrm{SeH}$ & 51.0 & -0.5 & -0.5 \\
\hline \multirow[t]{2}{*}{ PA } & $\mathrm{Br}$ & 322.6 & -1.4 & -1.6 \\
\hline & $\mathrm{CH}_{3} \mathrm{Br}$ & 157.3 & 0.1 & 0.0 \\
\hline MSD & & & -0.03 & 0.05 \\
\hline MAD & & & 0.88 & 0.92 \\
\hline
\end{tabular}

${ }^{a}$ Molecular second-order SO corrections are from ref $31 .{ }^{b}$ Experimental results are obtained from ref 14 .

element-containing molecules, which unfortunately describes the majority of the third-row G3/05 ionic species. 
In Table 3, ccCA-P and ccCA-S4 deviations are given when second-order atomic and molecular SO corrections are included in the energies. Clearly these effects are important in determining ionization energies, atomization energies, and $\Delta H_{\mathrm{f}}$ values for third-row species. Inclusion of these effects improves the MAD of ccCA-P from 0.95 to $0.88 \mathrm{kcal} \mathrm{mol}^{-1}$ and ccCA-S4 from 1.00 to $0.92 \mathrm{kcal} \mathrm{mol}^{-1}$, putting them on par with the G4 model chemistry. By including second-order SOC corrections, 25 of the ccCA-P deviations are improved by more than $0.1 \mathrm{kcal} \mathrm{mol}^{-1}$, while the errors are worse for 18 species. Overall, atomic second-order SOC corrections seem to improve the reliability of enthalpies of formation computed for larger molecules in the G3/05 training set.

C. Systems that Contain Gallium and Germanium Atoms and Electronegative Ligands. For gallium and germanium compounds, the $2 s$ basis functions on electronegative ligand atoms can substantially mix with the $3 d$ basis functions on the electropositive elements $\mathrm{Ga}$ and $\mathrm{Ge}$. Yamaguchi, Schaefer, and co-workers ${ }^{56,57}$ originally suggested that including the $3 d$ MOs in the correlation space when carrying out ab initio studies on Ga-containing molecules is a necessity, and further examples were presented by Duke and Radom ${ }^{58}$ and Bauschlicher and co-workers. ${ }^{59}$ Petersson and co-workers have devised an MO overlap scheme to determine a priori if molecules containing $\mathrm{Ga}-$ $\mathrm{Kr}$ atoms might be problematic. ${ }^{60}$ Martin and Sundermann have created a set of relativistic effective core potentials that include $3 d$ core correlation for Ga and Ge. ${ }^{61}$ There is a history of challenges in the study of these molecules including large uncertainties in the experimental enthalpies of formation, and we believe that relativistic coupled cluster calculations employing core-valence correlation effects (with the newly created core-valence basis sets) will be necessary to help pinpoint the source of errors.

Difficulties in computing energetics of molecules containing elements $\mathrm{Ga}-\mathrm{Kr}$ is thus far limited to systems with $\mathrm{Ga}-$ $\mathrm{O}, \mathrm{Ga}-\mathrm{F}$, and $\mathrm{Ge}-\mathrm{F}$ bonds. If the $3 d$ electrons are treated in the frozen core approximation, errors in energetic properties of more than $90 \mathrm{kcal} \mathrm{mol}^{-1}$ can occur, as in the case of the $\mathrm{G} 2$ atomization energy of $\mathrm{GaF}_{3} .{ }^{59}$ Unfortunately, preliminary results indicate the ccCA model chemistry may also be susceptible to unusually large errors when determining the correlation energy of such species. Using ccCA-P, the deviation from experiment for the atomization energy of $\mathrm{GaF}_{3}$ is $12.4 \mathrm{kcal} \mathrm{mol}^{-1}$. Inclusion of the $3 d \mathrm{MO}$ space in valence energy computations also improves some ccCA atomization energies but is not a panacea. More research is currently underway to provide a detailed analysis of the ccCA performance upon these Ga- and Ge-containing species.

\section{Conclusions}

The correlation consistent composite approach (ccCA) methodology has been applied to 51 atomic and molecular properties for elements $\mathrm{Ga}-\mathrm{Kr}$ in the $\mathrm{G} 3 / 05$ training set. The ccCA energies have been compared to other widely used model chemistries. Several conclusions have resulted from this research, the most important of which are summarized here.
(1) The ccCA methodology performs better than the G3 and G3X model chemistries, with a mean absolute deviation of $0.95-1.00 \mathrm{kcal} \mathrm{mol}^{-1}$ when first-order spin-orbit corrections are used.

(2) The core-valence additive correction to the ccCA energy is essential for a proper description of the relevant properties contained in the G3/05 training set. In fact, the MP2-based ccCA method is competitive with valence basis set CBS extrapolated $\operatorname{CCSD}(\mathrm{T})$ studies. We propose that this is due to the better modeling of core-valence electron correlation in the ccCA method as compared to the published CBS coupled cluster approaches.

(3) While adding spin-orbit corrections to atoms and molecules containing $4 p$ and heavier elements detracts from the "black box" nature of ccCA and $\mathrm{G} n$ methods, spinorbit coupling is a physical phenomenon that cannot be ignored when computing thermodynamic and energetic properties of such species. The addition of second-order spin orbit corrections results in a substantial improvement to the accuracy of the ccCA, as the MAD drops from 0.95 and $1.00 \mathrm{kcal} \mathrm{mol}^{-1}$ to 0.88 and $0.92 \mathrm{kcal} \mathrm{mol}^{-1}$ for ccCA-P and ccCA-S4, respectively.

For well-behaved third-row p-block molecules, the ccCA is thus a viable alternative to other model chemistries that rely on semiempirical corrections to the correlation energy. Furthermore, the modeling of heavier p-block elements is an important step on the way to developing a pan-periodic table composite method that is capable of yielding accurate thermodynamics.

Acknowledgment. CASCaM is supported by a grant from the United States Department of Education. This research is partially supported by a grant from the United States Department of Energy, Office of Basic Energy Sciences (to T.R.C.), Grant No. DE-FG02-03ER15387, and by a National Science Foundation CAREER Award CHE0239555 (to A.K.W.). Computational resources were provided via the National Science Foundation (CHE-0342824) and by the National Computational Science Alliance under \#CHE010021 and utilized the NCSA IBM p690. Some computations employed the UNT computational chemistry resource, whose purchase was supported by a CRIF grant from the U.S. National Science Foundation (CHE-0342824).

Supporting Information Available: Equilibrium B3LYP/cc-pVTZ equilibrium geometries (Table S1) and the complete citation for ref 36 . This material is available free of charge via the Internet at http://pubs.acs.org.

\section{References}

(1) DeYonker, N. J.; Cundari, T. R.; Wilson, A. K. J. Chem. Phys. 2006, 124, 114104.

(2) DeYonker, N. J.; Grimes, T.; Yockel, S.; Dinescu, A.; Mintz, B.; Cundari, T. R.; Wilson, A. K. J. Chem. Phys. 2006, 125, 104111.

(3) Dunning, T. H., Jr. J. Chem. Phys. 1989, 90, 1007.

(4) Dunning, T. H., Jr.; Peterson, K. A.; Wilson, A. K. J. Chem. Phys. 2001, 114, 9244.

(5) Balabanov, N. B.; Peterson, K. A. J. Chem. Phys. 2005, 123, 064107. 
(6) Peterson, K. A.; Dunning, T. H., Jr. J. Chem. Phys. 2002, 117, 10548.

(7) Woon, D. E.; Dunning, T. H., Jr. J. Chem. Phys. 1993, 98, 1358.

(8) Woon, D. E.; Dunning, T. H., Jr. J. Chem. Phys. 1994, 100, 2975.

(9) Woon, D. E.; Dunning, T. H., Jr. J. Chem. Phys. 1995, 103, 4572 .

(10) Wilson, A. K.; Woon, D. E.; Peterson, K. A.; Dunning, T. H., Jr. J. Chem. Phys. 1999, 110, 7667.

(11) Curtiss, L. A.; Redfern, P. C.; Raghavachari, K. J. Chem. Phys. 2005, 123, 124017.

(12) Curtiss, L. A.; Raghavachari, K.; Redfern, P. C.; Rassolov, V.; Pople, J. A. J. Chem. Phys. 1998, 109, 7764.

(13) Curtiss, L. A.; Raghavachari, K. Theor. Chem. Acc. 2002, $108,61$.

(14) Curtiss, L. A.; Redfern, P. C.; Rassolov, V.; Kedziora, G.; Pople, J. A. J. Chem. Phys. 2001, 114, 9287.

(15) Curtiss, L. A.; Redfern, P. C.; Raghavachari, K.; Pople, J. A. J. Chem. Phys. 2001, 114, 108.

(16) DeYonker, N. J.; Cundari, T. R.; Wilson, A. K.; Sood, C. A.; Magers, D. H. J. Mol. Struct. (Theochem) 2006, 775, 77.

(17) Ho, D. S.; DeYonker, N. J.; Wilson, A. K.; Cundari, T. R. J. Phys. Chem. A 2006, 110, 9767.

(18) DeYonker, N. J.; Peterson, K. A.; Steyl, G.; Wilson, A. K.; Cundari, T. R. J. Phys. Chem. A 2007, 111, 11269.

(19) DeYonker, N. J.; Ho, D. S.; Wilson, A. K.; Cundari, T. R. J. Phys. Chem. A 2007, 111, 10776.

(20) Martin, J. M. L.; de Oliveira, G. J. Chem. Phys. 1999, 111, 1843.

(21) Karton, A.; Rabinovich, E.; Martin, J. M. L.; Ruscic, B. J. Chem. Phys. 2006, 125, 144108.

(22) Tajti, A.; Szalay, P. G.; Császár, A. G.; Kallay, M.; Gauss, J.; Valeev, E. F.; Flowers, B. A.; Vazquez, J.; Stanton, J. F. J. Chem. Phys. 2004, 121, 11599.

(23) Dixon, D. A.; Feller, D.; Francisco, J. S. J. Phys. Chem. A 2003, 107, 186.

(24) Feller, D.; Dixon, D. A. J. Phys. Chem. A 2000, 104, 3048.

(25) Feller, D.; Dixon, D. A.; Francisco, J. S. J. Phys. Chem. A 2003, 107, 1604.

(26) Feller, D.; Peterson, K. A. J. Chem. Phys. 1998, 108, 154.

(27) Feller, D.; Peterson, K. A. J. Chem. Phys. 1999, 110, 8384.

(28) Feller, D.; Peterson, K. A.; Crawford, T. D. J. Chem. Phys. 2006, 124.

(29) Feller, D.; Peterson, K. A.; de Jong, W. A.; Dixon, D. A. J. Chem. Phys. 2003, 118, 3510.

(30) Pollack, L.; Windus, T. L.; de Jong, W. A.; Dixon, D. A. J. Phys. Chem. A 2005, 109, 6934.

(31) Blaudeau, J. P.; Curtiss, L. A. Int. J. Quantum Chem. 1997, 61, 943.

(32) Redfern, P. C.; Blaudeau, J. P.; Curtiss, L. A. J. Phys. Chem. A 1997, 101, 8701 .

(33) Blaudeau, J. P.; McGrath, M. P.; Curtiss, L. A.; Radom, L. J. Chem. Phys. 1997, 107, 5016.
(34) Curtiss, L. A.; McGrath, M. P.; Blaudeau, J. P.; Davis, N. E.; Binning, R. C., Jr.; Radom, L. J. Chem. Phys. 1995, 103, 6104.

(35) DeYonker, N. J.; Peterson, K. A.; Wilson, A. K. J. Phys. Chem. A 2007, 111, 11383.

(36) Frisch, M. J. et al. Gaussian 03, Revision C.02; Gaussian, Inc.: Wallingford, CT, 2004.

(37) Peterson, K. A.; Woon, D. E.; Dunning, T. H., Jr. J. Chem. Phys. 1994, 100, 7410.

(38) Martin, J. M. L.; Lee, T. J. Chem. Phys. Lett. 1996, 258, 136.

(39) Martin, J. M. L. Chem. Phys. Lett. 1996, 259, 669.

(40) Helgaker, T.; Klopper, W.; Koch, H.; Noga, J. J. Chem. Phys. 1997, 106, 9639.

(41) de Jong, W. A.; Harrison, R. J.; Dixon, D. A. J. Chem. Phys. 2001, 114, 48.

(42) Hess, B. A. Phys. Rev. A 1986, 33, 3742.

(43) Hess, B. A. Phys. Rev. A 1985, 32, 756.

(44) Douglas, M.; Kroll, N. M. Ann. Phys. 1974, 82, 89.

(45) The algorithm of ccCA in ref 2 uses an ROHF reference wave function for the scalar relativistic correction. We have found that using a UHF reference with a Douglas-Kroll-Hess Hamiltonian in Gaussian03 for the DK energies shifts enthalpies of formation by less than $0.01 \mathrm{kcal} \mathrm{mol}^{-1}$. This modification can be substituted for consistency and/or convenience.

(46) Moore, C. E. Atomic Energy Levels; U.S. Department of Commerce: Washington, DC, 1971; Vol. 2.

(47) Curtiss, L. A.; Redfern, P. C.; Raghavachari, K. J. Chem. Phys. 2007, 126.

(48) Petersson, G. A.; Bennett, A.; Tensfeldt, T. G.; Al-Laham, M. A.; Shirley, W. A.; Mantzaris, J. J. Chem. Phys. 1988, $89,2193$.

(49) Ochterski, J. W.; Petersson, G. A.; Montgomery, J. A. J. J. Chem. Phys. 1996, 104, 2598.

(50) Petersson, G. A.; Al-Laham, M. A. J. Chem. Phys. 1991, 94, 6081.

(51) Ramakrishna, V.; Duke, B. J. J. Chem. Phys. 2003, 118, 6137.

(52) Yockel, S.; Wilson, A. K. J. Chem. Phys. 2005, 122.

(53) Yockel, S.; Mintz, B.; Wilson, A. K. J. Chem. Phys. 2004, 121,60 .

(54) Hess, B. A.; Marian, C. M.; Peyerimhoff, S. D. Ab initio Calculation of Spin-Orbit Effects in Molecules Including Electron Correlation. In Modern Electronic Structure Theory, Vol. 2 of Advanced Series in Physical Chemistry; Yarkony, D. R., Ed.; World Scientific: Singapore, 1995; Vol. 2, p 152.

(55) Peterson, K. A. J. Chem. Phys. 1995, 102, 262.

(56) Yamaguchi, Y.; Schaefer, H. F. J. Chem. Phys. 1996, 104, 9841.

(57) Richards, C. A. J.; Yamaguchi, Y.; Kim, S.-J.; Schaefer, H. F. J. Chem. Phys. 1996, 104, 8516.

(58) Duke, B. J.; Radom, L. J. Chem. Phys. 1998, 109, 3352. 
(59) Bauschlicher, C. W., Jr.; Melius, C. F.; Allendorf, M. D. J. Chem. Phys. 1999, 110, 1879.

(60) Austin, A. J.; Frisch, M. J.; Montgomery, J. A.; Petersson, G. A. Theor. Chem. Acc. 2002, 107, 180.
(61) Martin, J. M. L.; Sundermann, A. J. Chem. Phys. 2001, 114, 3408 .

CT7002463 